\title{
Social Work Students' Attitudes and Skills Self-Efficacy Toward Collaborative Practice Improve After Interprofessional Opioid Use Disorder Case Discussion
}

\author{
Isok Kim \\ Diane E. Elze \\ Patricia J. Ohtake
}

\begin{abstract}
Few studies have examined social work student outcomes after engagement in interprofessional (IP) learning experiences. We examined self-reported attitudes and skills self-efficacy among social work students before and after their engagement in IP Forums. The data comes from social work students who participated in 2016-2018 Fall IP Forums focusing on opioid use disorder. Using the Interprofessional Attitudes Scale (IPAS) and the Interprofessional Collaborative Competency Attainment Scale, revised (ICCAS), we assessed students' self-reported attitudes (IPAS) and skills self-efficacy (ICCAS) before and after the Fall IP Forums. Paired t-tests identified significant changes in IPAS and ICCAS scores. Students reported increases in their IP attitudes and skills self-efficacy following participation in the IP Forum as measured by pre-IPAS score $(n=236, M=4.56$, $S D=0.29)$ to post-IPAS score $(M=4.68, S D=0.27 ; t(156)=-5.31, p<.001)$. Post-ICCAS score also increased $(n=48, M=4.26, S D=0.69 ; t(33)=-5.75, p<.001)$ from the pre-ICCAS score $(M=3.55, S D=0.92)$. The 2015 Council on Social Work Education Accreditation Standards require that social work students learn how to value and engage in interprofessional teams. Given the self-reported increases in IP attitudes and skills selfefficacy seen in this study, IP Forum participation will help foster greater engagement and contribution to overall IP experiences for social work students.
\end{abstract}

Keywords: Interprofessional education; collaboration, opioid use disorder, Interprofessional Attitudes Scale, Interprofessional Collaborative Competency Attainment Scale

The integration of interprofessional (IP) education into the 2015 Educational Policy and Accreditation Standards Council on Social Work Education (CSWE) requires social work (SW) students to learn how to value and engage in IP teams. The CSWE accreditation standards assert the importance of social workers' understanding of the roles of other professions when engaged in IP teams and valuing interprofessional collaboration in engagement, assessment, and interventions (CSWE \& Commission on Accreditation and Commission on Educational Policy, 2015).

In response, SW programs have begun to integrate interprofessional education (IPE) into their curricula (Bonifas, 2017; Elze et al., 2017; Macmillan \& Rejent, 2017; Rubin, et al., 2018). While a robust body of research has examined IP attitudes and skills among students across many health professions (e.g., Kent \& Keating, 2015; Olson \&

Isok Kim, Associate Professor and Director of MSW Program, School of Social Work; Diane E. Elze, Associate Professor and Associate Dean for Academic Affairs, School of Social Work; Patricia J. Ohtake, Assistant Vice President for Interprofessional Education, Office of the Vice President for Health Sciences; Associate Professor, Physical Therapy Program, Department of Rehabilitation Science, School of Public Health and Health Professions, University at Buffalo, Buffalo, NY. 
Bialocerkowski, 2014; Reeves et al., 2016), fewer investigations have examined SW students' engagement with IP learning experiences (e.g., Park et al., 2014).

Among the limited studies, the findings are mixed regarding SW students' attitudes towards IP collaboration following engagement in IPE (e.g., Addy et al., 2015; Park et al., 2014). On one hand, some studies found a positive impact of IPE among SW students. For example, Curran, Sharpe, Forristall, and Flynn (2008) found that SW students reported the highest mean satisfaction score for small IP group learning methods compared to their counterparts from medicine, nursing, and pharmacy. Ko, Bailey-Kloch, and Kim (2014) also found that SW students reported a positive attitude towards IP collaboration when improving the overall quality of care for patients.

However, other studies found negative outcomes associated with IPE. Park et al. (2014) found that SW students reported the least positive attitudes when collaborating with physicians. Lidskog, Löfmark, and Ahlström (2007) found in their qualitative study that SW students reportedly felt like an outsider and needed to depend on other professionals to do their job. West, Miller, and Leitch (2016) found that SW students reported perceptions of lower prestige when thinking about participating in IP collaboration with students in medicine, nursing, and pharmacy.

Notwithstanding that most of these studies contained a small number of SW students as study participants, the inconsistent findings suggest that there is a need for more empirical studies with more participants. Thus, our study addresses this research gap. We examined self-reported attitudes and skills self-efficacy among a large cohort of social work students enrolled at the University at Buffalo before and after their engagement in Fall IP Forums in 2016, 2017 and 2018 that focused on the public health crisis of opioid use disorder.

\section{Interprofessional Education at the University at Buffalo}

The University at Buffalo established the Office of Interprofessional Education to develop and implement interprofessional educational and clinical experiences that address the Interprofessional Education Collaborative (IPEC) core competencies for collaborative practice (IPEC, 2016; IPEC Expert Panel, 2011). The Office of IPE is supported by the university's schools of Medicine and Biomedical Sciences, Dental Medicine, Nursing, Pharmacy and Pharmaceutical Sciences, Public Health and Health Professions, and Social Work. Since 2016, the Office of IPE has held a Fall IP Forum, "Confronting Opioid Dependence: An Interprofessional Strategy," to educate students about the opioid epidemic and the necessity of IP collaboration to address this public health crisis at both the individual and population levels. The Fall IP Forum, which enrolls approximately 900 students from 12 health professions, is an exposure level IP activity that introduces students to the importance of IP collaborative practice, the unique roles and responsibilities of the different professions, and IP communication and teamwork skills.

\section{Pre-IP Forum Preparation}

The Office of IPE's Faculty Leadership Team collectively developed a case study for the Fall IP Forum that presents students with a portrayal of a female patient with opioid 
dependence, other chronic health conditions, and complex psychosocial challenges. Prior to the Fall IP Forum, students completed three online modules from the online module series, Foundations of Interprofessional Collaboration, developed by faculty associated with the Office of IPE: (a) a welcome from the Vice President for Health Sciences, (b) Introduction to IP Collaborative Practice, and (c) Roles and Responsibilities. They also viewed several brief videos about opioid dependence (total of 31 minutes); completed a pre-assessment; and reviewed the case study.

One faculty facilitator was assigned to each IP group of $\sim 7$ students. In preparation for their role as IP small group facilitators, faculty were asked to view the same videos as the students and were equipped with a Faculty Facilitator Guide, which provided a detailed summary of pre-Fall IP Forum preparation activities, the Fall IP Forum schedule, student learning objectives, the IPEC competencies addressed by the Fall IP Forum, and detailed instructions for the small group activities. Faculty were also given a Case Facilitator Guide that outlined the physical and mental health, and psychosocial issues relevant to the case, organized by profession, to facilitate discussion of roles of professions not represented in their small group. Additionally, the Office of IPE offered Interprofessional Small Group Facilitator Training that facilitators completed prior to the Fall IP Forum. This training was offered in three formats: written instructions, online video, and a 30-minute Just-in-Time Training held immediately prior to each Fall IP Forum session.

\section{Format of the Fall IP Forum}

Each Fall IP Forum was offered three times during the day (i.e., morning, afternoon, and evening). Each session accommodated approximately 300 students, for a total of $\sim 900$ students from the 12 participating health professions education programs. Students convened in a large lecture hall to hear short keynote addresses about the opioid epidemic from the population health and individual health perspectives. The County Commissioner of Health described the prevalence, causes, consequences of, and effective interventions to address opioid dependence. Another healthcare provider described the importance of medication-assisted treatment and the need to reduce stigma and bias to optimize patient outcomes. Students then dispersed to their pre-assigned, faculty-facilitated, interprofessional discussion groups. Within their small group ( $\sim 7$ students), the participants introduced themselves, reviewed guiding principles for the small group (e.g., fully participate, model respect for your colleagues and for yourself), and engaged in an initial activity to share information about their professions' roles and responsibilities and correct any misperceptions about their professions.

Following the initial discussion, students then proceeded to develop a comprehensive list of the issues experienced by the patient described in the case. Collaboratively, the group developed an integrated IP plan of care. A faculty facilitator then conducted a short debriefing with all groups assembled in the room, asking the groups: (a) What was something you learned about another profession that you did not know before? (b) What worked well within your group? (c) What did you learn today that you will incorporate into your clinical practice? Following the small group discussion, students completed postassessments and a program evaluation. 


\section{Method}

\section{Sample}

SW master's level students that participated in the 2016, 2017, or 2018 Fall IP Forum were included in the study, with equal representation from foundation and advanced year students. IRB approval was received for this study from the Social and Behavioral Sciences IRB Committee at the University at Buffalo. The study is a records review and received exempt status.

\section{Measures}

We used two measures to assess students' self-reported attitudes and skills selfefficacy before and after the IP activities associated with the Fall IP Forum: the Interprofessional Attitudes Scale (IPAS, Norris et al., 2015) and the Interprofessional Collaborative Competency Attainment Scale, revised (ICCAS, Schmitz et al., 2017).

The IPAS measures students' self-reported attitudes that are aligned with the 2011 IPEC's four core competencies (i.e., Values/Ethics; Roles/Responsibilities; IP Communication; and Teams and Teamwork; IPEC Expert Panel, 2011) using a 5-point Likert scale (1=Strongly Disagree to $5=$ Strongly Agree). The IPAS was administered in all three $(2016,2017,2018)$ Fall IP Forums.

The ICCAS measures self-reported ability (self-efficacy) to perform the IPEC Core Competencies using a 5-point Likert Scale $(1=$ Poor to $5=$ Excellent $)$. The ICCAS has been used in past literature with good reliability (e.g., Langford et al., 2019). The ICCAS was administered only in the 2018 Fall IP Forum.

\section{Data Analysis}

The analyses were conducted using Stata SE version 12. Descriptive statistics are provided for sample characteristics, including age, gender identity, and prior IP experiences. Paired t-tests were used to examine any significant differences in pre- and post-test results for IPAS and ICCAS scores. Significance was set at $p<0.05$.

\section{Results}

Participants included SW students who participated in one of the three Fall IP Forums between 2016 and 2018, for whom the data $(n=236)$ were aggregated. The majority of the participants self-identified as female $(88.8 \%)$ with an average age of $28.2(\mathrm{SD}=9.9)$ years. One hundred nine $(46.2 \%)$ students reported having prior IP experiences, defined as any IP experiences in which they participated in the past through personal, work, and/or academic settings. Table 1 shows sample characteristics by year of Fall IP Forum attendance. 
Table 1. Sample Characteristics $(n=236)$.

\begin{tabular}{lcccc}
\hline & $\begin{array}{c}2016 \\
(\mathrm{n}=126)\end{array}$ & $\begin{array}{c}2017 \\
(\mathrm{n}=62)\end{array}$ & $\begin{array}{c}2018 \\
(\mathrm{n}=48)\end{array}$ & $\begin{array}{c}\text { All } \\
(\mathrm{n}=236)\end{array}$ \\
\cline { 2 - 5 } Age & \multicolumn{4}{c}{ Avg Years (SE) } \\
\hline \multicolumn{5}{c}{$\mathrm{n}(\%)$} \\
Gender, Female \% & $114(90.2 \%)$ & $53(85.5 \%)$ & $43(89.4 \%)$ & $210(88.8 \%)$ \\
Has prior IP Exp. & - & $29(46.8 \%)$ & $47(97.9 \%)$ & $109(46.2 \%)$ \\
\hline Note: The data regarding prior IP experiences for SW students are not available for the 2016 Fall IP \\
Forum.
\end{tabular}

The Cronbach's alphas (Table 2) were calculated to examine the reliability of the preand post-IPAS subscale scores for IPAS-TRR (Teamwork, Roles, Responsibilities), IPASPC (Patient-centeredness), IPAS-IB (Interprofessional Biases), IPAS-DE (Diversity \& Ethics), and IPAS-CC (Community-centeredness). The Cronbach's alphas of all pre- and post-scores on the IPAS subscales were 0.77 or higher, except for the IPAS-IB $(\alpha=0.66)$, which is considered minimally acceptable reliability range for measures with low stakes (Nunnaly, 1978; Ponterotto \& Ruckdeschel, 2007).

Similar to the IPAS, the Cronbach's alphas (Table 2) were calculated to examine the reliability of the pre- and post-ICCAS subscale scores of ICCAS-COM (Communication), ICCAS-COL (Collaboration), ICCAS-RR (Roles \& Responsibilities), ICCAS-PFC (Collaborative Patient \& Family-centered Approach), and ICCAS-CMR (Conflict Management \& Resolution). All ICCAS subscales had Cronbach's alpha scores of 0.85 or higher, which is considered excellent. Table 2 shows the means, standard deviations and Cronbach's alphas for IPAS and ICCAS subscales.

Table 2. The calculated means and internal consistency for composite and subscales of the IPAS $(n=236)$ and the ICCAS $(n=48)$ in this study

\begin{tabular}{l|c:c}
\hline Measures & Items & $\begin{array}{c}\text { Cronbach's Alpha } \\
\text { (Pre/Post) }\end{array}$ \\
\hline Interprofessional Attitudes Scale (IPAS)-Composite & 27 & $0.83 / 0.83$ \\
Teamwork/Roles/Responsibilities (IPAS-TRR) & 9 & $0.84 / 0.85$ \\
Patient-centeredness (IPAS-PC) & 5 & $0.77 / 0.92$ \\
Interprofessional biases (IPAS-IB) & 3 & $0.66 / 0.66$ \\
Diversity/ethics (IPAS-DE) & 4 & $0.79 / 0.85$ \\
Community-centeredness (IPAS-CC) & 6 & $0.89 / 0.92$ \\
\hline Interprofessional Collaborative Competency Attainment & 20 & $0.98 / 0.99$ \\
Scale (ICCAS)-Composite & & \\
Communication (ICCAS-COM) & 5 & $0.93 / 0.92$ \\
Collaboration (ICCAS-COL) & 3 & $0.95 / 0.95$ \\
Roles and responsibilities (ICCAS-RR) & 4 & $0.92 / 0.95$ \\
Collaborative patient-/family-centered approach & 3 & $0.85 / 0.95$ \\
$\quad$ (ICCAS-PFC) & & \\
Conflict management and resolution (ICCAS-CMR) & 3 & $0.93 / 0.87$ \\
Team functioning (ICCAS-TF)* & 2 & - \\
\hline
\end{tabular}

*TF subscale only consists of two items, which is not enough to calculate Cronbach's alpha. 
SW students reported strongly positive overall attitudes toward IP collaboration prior to the Fall IP Forum as measured by the IPAS $(M=4.56, S D=0.29$; Table 3). Students' overall attitudes toward IP collaboration showed a small, yet significant increase following the Fall IP Forum as evidenced by their post-IPAS composite score $(M=4.68, S D=0.27$; $t(156)=-5.31, p<.001)$. Examining the changes in the IPAS subscale scores (Table 3), there were increases in positive attitudes in the subscales of Teamwork, Roles, Responsibilities; Interprofessional Biases; and Community-centeredness. Additionally, post-hoc analyses showed that there was no statistically significant difference of pre-IPAS score between those with $(M=4.59, S D=0.29)$ and without $(M=4.54, S D=0.28)$ prior IP experience $(t(155)=-1.09, p=0.28)$.

Prior to the Fall IP Forum, SW students' perceived self-efficacy in performing the skills associated with the IPEC Core Competencies averaged between Good and Very Good on the ICCAS $(M=3.55, S D=0.92)$. Following participation in the Fall IP Forum, SW students' perceived self-efficacy increased as shown by the post-ICCAS composite score $(M=4.26, S D=0.69 ; t(33)=-5.751, p<.001)$. Examination of the changes in the subscale scores (Table 3 ) shows that all subscale scores improved following participation in the Fall IP Forum.

Table 3. The results of paired t-tests between pre- and post-Fall IP Forum IPAS and ICCAS assessments (composite and subscales) and their corresponding effect sizes.

\begin{tabular}{|c|c|c|c|c|c|c|}
\hline Scales & $\begin{array}{c}\text { Means } \\
\text { (pre/post) }\end{array}$ & $\begin{array}{l}\text { Std. Dev. } \\
\text { (pre/post) }\end{array}$ & $\mathbf{d}(\mathbf{f})$ & $\mathbf{t}$ & p-value & $\begin{array}{c}\text { Cohen's } \\
d\end{array}$ \\
\hline IPAS-Composite & $4.56 / 4.68$ & $0.29 / 0.27$ & 156 & -5.314 & $<.001^{*}$ & .411 \\
\hline IPAS-TRR & $4.49 / 4.65$ & $0.50 / 0.48$ & 157 & -4.128 & $<.001 *$ & .334 \\
\hline IPAS-PC & $4.90 / 4.92$ & $0.23 / 0.36$ & 156 & -0.565 & .573 & .059 \\
\hline IPAS-IB & $3.43 / 3.71$ & $0.88 / 0.87$ & 155 & -4.108 & $<.001 *$ & .312 \\
\hline IPAS-DE & $4.88 / 4.89$ & $0.30 / 0.30$ & 155 & -0.491 & .624 & .043 \\
\hline IPAS-CC & $4.74 / 4.85$ & $0.40 / 0.34$ & 155 & -3.695 & $<.001 *$ & .288 \\
\hline ICCAS-Composite & $3.55 / 3.73$ & $0.92 / 0.94$ & 33 & -5.751 & $<.001 *$ & .879 \\
\hline ICCAS-COM & $3.73 / 4.25$ & $0.94 / 0.67$ & 33 & -4.700 & $<.001 *$ & .643 \\
\hline ICCAS-COL & $3.46 / 4.24$ & $1.07 / 0.77$ & 33 & -4.742 & $<.001^{*}$ & .844 \\
\hline ICCAS-RR & $3.44 / 4.26$ & $0.98 / 0.73$ & 33 & -6.225 & $<.001 *$ & .961 \\
\hline ICCAS-PFC & $3.50 / 4.24$ & $0.99 / 0.77$ & 33 & -5.056 & $<.001 *$ & .841 \\
\hline ICCAS-CMR & $3.72 / 4.38$ & $0.94 / 0.66$ & 33 & -4.993 & $<.001 *$ & .835 \\
\hline ICCAS-19(TF) & $3.29 / 4.15$ & $0.18 / 0.13$ & 33 & -5.575 & $<.001 *$ & .946 \\
\hline ICCAS-20(TF) & $3.35 / 4.21$ & $0.19 / 0.14$ & 33 & -6.055 & $<.001 *$ & .929 \\
\hline
\end{tabular}

Note: IPAS=Interprofessional Attitudes Scale; TRR=Teamwork/Roles/Responsibilities; PC=Patientcenteredness; $\mathrm{IB}=$ Interprofessional biases; $\mathrm{DE}=$ Diversity/ethics; $\mathrm{CC}=$ Community-centeredness. $\mathrm{ICCAS}=$ Interprofessional Collaborative Competency Attainment Scale; $\mathrm{COM}=$ Communication; $\mathrm{COL}=$ Collaboration; $\mathrm{RR}=$ Roles and responsibilities; $\mathrm{PFC}=$ Collaborative patient/family-centered approach; $\mathrm{CMR}=$ Conflict management and resolution; $\mathrm{TF}=$ Team functioning. ${ }^{*}$ significant $=\mathrm{p}<.001$

Following the best practice standard of interpreting Cohen's $d$ scores (Cohen, 1988; Kirk, 2001), we were able to determine that all of the IPAS subscales with statistically significant pre/post changes showed small effect sizes. On the other hand, all of the ICCAS subscale differences showed large effect sizes. 


\section{Discussion}

The purpose of this research was to examine the changes in SW students' self-reported attitudes and skills self-efficacy in IP collaborative practice before and after participating in the Fall IP Forums at the University at Buffalo. This study employed a large number of SW students who participated in one of three Fall IP Forums between 2016 and 2018. Overall, this study's findings were consistent with previous literature (e.g., Curran et al., 2008; Ko et al., 2014) that found a positive association between participation in IP activities and an increase in attitudes and skills self-efficacy related to the IPEC competencies. It is important to note that SW students in this study reported very high initial scores in the IPAS, and they scored even higher after their participation in the IP Forum. On the contrary, their initial ICCAS scores were lower but improved significantly after their IP Forum participation. This suggests that while SW students have positive attitudes toward collaboration (IPAS), they report lower levels of self-efficacy in the ability to perform the IPEC core competency skills. Providing the SW students with experiential learning seems to have contributed to improving their self-efficacy in all skills self-efficacy components measured by the ICCAS (i.e., Communication, Collaboration, Roles and responsibilities, Collaborative patient-/family-centered approach, Conflict management and resolution, and Team functioning). The comparisons between the pre- and post-Fall IP Forum scores for the IPAS and the ICCAS measures indicated that SW students who participated in the Fall IP Forums improved in their self-reported attitudes and skills self-efficacy, which are essential for successfully working in an IP collaborative practice setting.

The subscales of IPAS and ICCAS measures were designed to assess self-reported attitudes and skills self-efficacy, respectively, related to the 2011 IPEC's four core competencies for IP collaborative practice. Self-reported attitudes toward three IPAS scales improved following Fall IP Forum participation: IPAS-TRR, IPAS-IB, and IPAS-CC. Changes in these subscales are consistent with the focus of the learning objectives and activities of the Fall IP Forum. With respect to the IPAS-TRR subscale, SW students were brought together to work in small groups as a healthcare team. Students shared their professional roles and responsibilities and collaborated to develop an integrated, IP plan of care. Considering the IPAS-IB subscale, this collaborative group activity served to reduce biases among students from differing professions through discussion that promoted a more accurate understanding of each of the health professions. Finally, the small group discussion also involved exploring the community and population-level strategies for the prevention and management of the current opioid health crisis. These discussions are consistent with the increase in positive attitudes toward community-centeredness and thus the IPAS-CC subscale score.

Two subscales of the IPAS did not change in response to participation in the Fall IP Forum. The IPAS-PC subscale is designed to measure perceived attitude around "patientcenteredness," which addresses the importance of establishing trust, communicating compassion, and understanding issues from a patient's perspective. This is not surprising as the IPAS-PC were the highest scores reported by the SW students $(4.90 \pm 0.23 / 5.00)$ prior to the Fall IP Forum and remained at this high level following the Fall IP Forum $(4.92 \pm 0.36 / 5.00)$. This same phenomenon has been observed in another study (Fusco et al., 2019) based on the same Fall IP Forum experience at the University at Buffalo, in which 
the authors found that the Pharmacy students' IPAS-PC scores were very high and did not significantly change after the IP Forum. The other subscale, IPAS-DE, deals with the importance of paying attention to the diversity and unique cultures of health professionals as well as serving anyone regardless of their background. The IPAS-DE subscale had the second-highest subscale score reported by the SW students $(4.88 \pm 0.30)$ and the score also remained at this very high level following the Fall IP Forum. Given the social work education's emphasis on the person-in-environment perspective and social justice mission, it is not surprising that the SW students in this study had reported high levels of attitudinal competencies on these two dimensions before the IP Forum.

On the other hand, the ICCAS measures self-efficacy in behavioral competencies as they relate to IP core competencies, including communication, collaboration, roles and responsibilities, collaborative patient/family-centered approach, conflict management/ resolution, and team functioning (MacDonald et al., 2010). Unlike the IPAS, the ICCAS was administered for the first time in the 2018 Fall IP Forum. Therefore, we only had a single data point to examine the changes in students' self-efficacy in the skills associated with the IPEC core competencies. Nonetheless, based on overall and subscale scores of the ICCAS, the SW students reported that their post-Fall IP Forum level of IPEC core competency self-efficacy improved from their pre-Fall IP Forum level in all areas. Though almost every SW student reported prior IP experiences, their changes in ICCAS scores yielded the large effect size. This could mean that IP Forum experience may be robust enough to further enhance the IP-related skills among SW students with prior IP experiences. The observed large effect size response is consistent with the ICCAS validation study (Archibald et al., 2014) and the replication of the ICCAS validation study (Schmitz et al., 2017), and has been reported by others following similar interprofessional learning experiences (Nagge et al., 2017).

It is worth noting that the ICCAS uses a retrospective PRE/real-time POST survey design (Archibald et al., 2014; Schmitz et al., 2017). This survey is deployed following the learning experience and asks students to reflect "on both their current and prior level of competency regarding IP collaboration." The survey designers believe this retrospective PRE/real-time POST survey design results in better identification of students' own weaknesses before completing IP activities (MacDonald et al., 2010).

Our study has important strengths and some limitations. The strengths of this study include a large sample size collected over several offerings of the Fall IP Forum. The large sample size provides the opportunity for more robust statistical analyses. Including data across several Fall IP Forums demonstrates the consistency of this learning experience to positively impact SW students' self-reported attitudes toward collaborative practice.

As is with any study, the results of our study must be interpreted in the context of its limitations. First, it is possible that SW students who willingly participated in the Fall IP Forums may be motivated and therefore possibly biased toward the positive nature of IP educational opportunities (Reeves et al., 2016). However, more than half of SW students $(n=126)$ in this study were required to participate by their instructors in the 2016 Fall IP Forum, which lessens the outright dismissal of the study's results due to self-selection bias alone. Second, we relied on the self-reported perceived attitudinal changes and skill 
improvements by the students, and therefore, observed improvements could be attributed to a social desirability bias. Third, this study was conducted at one large research-intensive university and may not be generalizable to other institutions. Lastly, the significant selfreported attitudinal and skill improvement identified in this study were captured within days after the Fall IP Forum participation and, therefore, maintenance of improved attitudes and skills cannot be ascertained into the future. It is possible that the initial excitement of learning and participating in an IP educational activity would wane once the students recognize the challenge of collaborative practice in real healthcare settings.

\section{Recommendations}

Even though social work as a profession is no stranger to IPE, social work scholars and educators are not always adequately represented in informing and developing IPE (Kobayashi \& Fitzgerald, 2017). At the University at Buffalo, this was not the case: The School of Social Work and its faculty representative (second author) were at the table from the exploration to inception phases, directly involved in informing and influencing the structure of the Office of IPE and the resulting Fall IP Forum. The current IP Leadership Team, which is led by the Assistant Vice President for Interprofessional Education (third author), includes the director of the MSW Program (first author). As a result, each time we offered the IP forums in the past, students in the other health professions have given consistent feedback year after year about the importance of having a social worker as a member of their team.

Fraser et al. (2018) emphasized in their systematic review that "integrated primary care provided by interprofessional teams that include social workers significantly improves the behavioral health and care of patients" (p. 175). What Fraser and his colleagues have found in their systematic review further solidifies the critical need for educating social work students through interprofessional collaborative practice framework. Our study found that SW students' significantly increased in their self-reported IP attitudes and skills selfefficacy after participating in our IP forum, an interprofessional collaborative educational opportunity. It is important that future social workers are well-prepared to work collaboratively in interprofessional settings like the healthcare system-doing so will help them to maximize their efficacy as social workers when they represent and advocate for clients.

Beginning the 2019-2020 academic year, SW students enrolled at the University at Buffalo were required to participate in the Fall and Spring IP Forums. Based on our study findings, the required IP Forum participation will likely increase social work students' IPrelated attitudes and skills and foster greater engagement and contribution to the overall IP experience for every student involved from all professions.

\section{References}

Addy, C. L., Browne, T., Blake, E. W., \& Bailey, J. (2015). Enhancing interprofessional education: Integrating public health and social work perspectives. American Journal of Public Health, 105(S1), S106-S108. https://doi.org/10.2105/ajph.2014.302502 
Archibald, D., Trumpower, D., \& MacDonald, C. J. (2014). Validation of the interprofessional collaborative competency attainment survey (ICCAS). Journal of Interprofessional Care, 28(6), 553-558. https://doi.org/10.3109/13561820.2014.917407

Bonifas, R. P. (2017). Arizona State University. In C. Morano (Ed.), Perspectives on interprofessional education and practice (pp. 137-156). Washington, DC: NASW Press.

Cohen, J. (1988). Statistical power analysis for the behavioral sciences (2nd ed.). Hillsdale, NJ: Lawrence Erlbaum.

Council on Social Work Educaiton [CSWE] \& Commission on Accreditation and Commission on Educational Policy. (2015). Educational Policy and Accreditation Standards for baccalaureate and master's social work programs. CSWE. Retrieved from https://www.cswe.org/getattachment/Accreditation/Accreditation-Process/2015EPAS/2015EPAS_Web_FINAL.pdf.aspx

Curran, V. R., Sharpe, D., Forristall, J., \& Flynn, K. (2008). Student satisfaction and perceptions of small group process in case-based interprofessional learning. Medical Teacher, 30(4), 431-433. https://doi.org/10.1080/01421590802047323

Elze, D. E., Wietig, P., \& Ohtake, P. J. (2017). University at Buffalo. In C. Morano (Ed.), Perspectives on interdisciplinary education and practice. NASW.

Fraser, M. W., Lombardi, B. M., Wu, S. Y., Zerden, L. D., Richman, E. L., \& Fraher, E. P. (2018). Integrated primary care and social work: A systematic review. Journal of the Society for Social Work and Research, 9(2), 175-215. https://doi.org/10.1086/697567

Fusco, N. M., Maerten-Rivera, J., Doloresco, F., \& Ohtake, P. J. (2019). Improving pharmacy students' attitudes toward collaborative practice through a large-scale interprofessional forum targeting opioid dependence. American Journal of Pharmaceutical Education, 83(6), 1226-1232. https://oi.org/10.5688/ajpe7034

Interprofessional Education Collaborative Expert Panel. (2011). Core competencies for interprofessional collaborative practice: Report of an expert panel. Interprofessional Education Collaborative. https://doi.org/10.1016/j.xjep.2015.07.037

Interprofessional Education Collaborative. (2016). Core competencies for interprofessional collaborative practice: 2016 update. Author. https://doi.org/10.1016/j.xjep.2015.07.037

Kent, F., \& Keating, J. L. (2015). Interprofessional education in primary health care for entry level students-A systematic literature review. Nurse Education Today, 35(12), 1221-1231. https://doi.org/10.1016/j.nedt.2015.05.005

Kirk, R. E. (2001). Promoting good statistical practices: Some suggestions. Educational and Psychological Measurement, 61(2), 213-218. https://doi.org/10.1177/00131640121971185 
Ko, J., Bailey-Kloch, M., \& Kim, K. (2014). Interprofessional experiences and attitudes toward interprofessional health care teams among health sciences students. Social Work in Health Care, 53(6), 552-567. https://doi.org/10.1080/00981389.2014.903884

Kobayashi, R., \& Fitzgerald, C. (2017). Teaching note-Asserting social work's role in developing an interprofessional education project. Journal of Social Work Education, 53(4), 737-743. https://doi.org/10.1080/10437797.2017.1284627

Langford, D. J., Gordon, D. B., Loeseer, J. D., Tauben, D. J., \& Doorenbos, A. Z. (2019). Evaluation of an interprofessional active learning session on acute pain and opioid use disorder using the interprofessional collaborative competency attainment scale. Journal of Interprofessional Care, 1-9. https://doi.org/10.1080/13561820.2019.1629398

Lidskog, M., Löfmark, A., \& Ahlström, G. (2007). Interprofessional education on a training ward for older people: Students' conceptions of nurses, occupational therapists and social workers. Journal of Interprofessional Care, 21(4), 387-399. https://doi.org/10.1080/13561820701349420

MacDonald, C. J., Archibald, D., Trumpower, D., Casimiro, L., Cragg, B., \& Jelley, W. (2010). Designing and operationalizing a toolkit of bilingual interprofessional education assessment instruments. Journal of Research in Interprofessional Practice and Education, 1(3), 304-316. https://doi.org/10.22230/jripe.2010v1n3a36

Macmillan, K., \& Rejent, D. (2017). The University of Maryland at Baltimore. In C. Morano (Ed.), Perspectives on interprofessional education and practice (pp. 125136). NASW Press.

Nagee, J., Lee-Poy, M., \& Richard, C. (2017). Evaluation of a unique interprofessional education program involving medical and pharmacy students. North American Journal of Pharmaceutical Education, 81(10), Article 6140. https://doi.org/10.5688/ajpe6140

Norris, J., Carpenter, J. G., Eaton, J., Guo, J.-W., Lassche, M., Pett, M. A., \& Blumenthal, D. K. (2015). The development and validation of the Interprofessional Attitudes Scale: Assessing the interprofessional attitudes of students in the health professions. Academic Medicine : Journal of the Association of American Medical Colleges, 90(10), 1394-1400. https://doi.org/10.1097/acm.0000000000000764

Nunnaly, J. C. (1978). Psychometric theory (2nd ed.). McGraw Hill.

Olson, R., \& Bialocerkowski, A. (2014). Interprofessional education in allied health: A systematic review. Medical Education, 48(3), 236-246. https://doi.org/10.1111/medu.12290

Park, J., Hawkins, M., Hamlin, E., Hawkins, W., \& Bamdas, J. A. M. (2014). Developing positive attitudes toward interprofessional collaboration among students in the health care professions. Educational Gerontology, 40(12), 894-908. https://doi.org/10.1080/03601277.2014.908619 
Ponterotto, J. G., \& Ruckdeschel, D. E. (2007). An overview of coefficient alpha and a reliability matrix for estimating adequacy of internal consistency coefficients with psychological research measures. Perceptual and Motor Skills, 105(3), 997-1014. https://doi.org/10.2466/pms.105.7.997-1014

Reeves, S., Fletcher, S., Barr, H., Birch, I., Boet, S., Davies, N., McFadyen, A., Rivera, J., \& Kitto, S. (2016). A BEME systematic review of the effects of interprofessional education: BEME Guide No. 39. Medical Teacher, 38(7), 656-668. https://doi.org/10.3109/0142159x.2016.1173663

Rubin, M., Cohen Konrad, S., Nimmagadda, J., Scheyett, A., \& Dunn, K. (2018). Social work and interprofessional education: Integration, intersectionality, and institutional leadership. Social Work Education, 37(1), 17-33. https://doi.org/10.1080/02615479.2017.1363174

Schmitz, C. C., Radosevich, D. M., Jardine, P., MacDonald, C. J., Trumpower, D., \& Archibald, D. (2017). The Interprofessional Collaborative Competency Attainment Survey (ICCAS): A replication validation study. Journal of Interprofessional Care, 31(1), 28-34. https://doi.org/10.1080/13561820.2016.1233096

West, A., Miller, S., \& Leitch, J. (2016). Professional socialization and attitudes towards interprofessional collaboration among graduate social work and health professions students. Advances in Social Work, 17(2), 134-150. https://doi.org/10.18060/19809

Author note: Address correspondence to Isok Kim, School of Social Work, University at Buffalo, 685 Baldy Hall, Buffalo, NY 14260. Email: isokkim@,buffalo.edu 